Educational Administration Quarterly Vol. 17, No. 3 (Summer 1981) 15-41

Robert A. Cooke

Denise M. Rousseau

\title{
Problems of Complex Systems: A Model of System Problem Solving Applied to Schools ${ }^{1}$
}

This article presents a model of problem solving that specifies the way in which system properties give rise to a set of generic problems that must be resolved by all organizations. The adequacy of an organization's problem solving is hypothesized to be related to the resources (inputs) available to the system and to the appropriateness of its structures. This model, including the relationship between problem solving adequacy and system outputs, is tested in a sample of twenty-five public schools.

Robert A. Cooke is Associate Research Scientist at the Institute for Social Research and Denise M. Rousseau is Assistant Professor in the Department of Psychology, The University of Michigan. (At the time this article was written, Cooke was a Visiting Scholar at the Stanford Institute for Research on Educational Finance and Governance and Rousseau was an Assistant Professor at the Naval Postgraduate School.)

\footnotetext{
$\mathbf{P}$ roblem solving in schools is a continuing concern in an age of declining enrollments, budget cuts, and the decreasing quality of teacher work life. ${ }^{2}$ Schools, like all systems open to their environments, face problems-that is, conditions producing tension or disturbances in the system's internal equilibrium. These problems, which are generated by the basic properties that characterize open systems, must be properly managed on an on-going basis by all organizations. The relevance of problem solving to system effectiveness and the organizational variables associated with successful problem solving have received considerable attention in the field of organizational theory. ${ }^{3}$ Although these issues are directly relevant to school organizations, they have received somewhat less attention in the area of educational administration.
} 
Building on the work of Georgopoulos and Cooke, Katz and Kahn, Rousseau, and others, this article presents a model of organizational problem solving for schools. ${ }^{4}$ The model focuses on system properties and a set of problems that all systems must solve in order to remain organized and viable. The model considers the importance of system inputs to the problem-solving process and the conditions under which inputs may lead to adequate problem solving. It also addresses the linkage between problem solving and the level of organizational outputs. As a partial test of the systems framework developed here, data from 25 elementary and secondary schools are used to examine the relationships among school funding, organizational structures, problem-solving adequacy, and school outputs.

\section{A MODEL OF SYSTEMS PROPERTIES AND PROBLEMS}

Though much has been written about the effectiveness and performance of complex organizations, there has been little convergence in this literature. Proponents of the two traditional models of organizational effectiveness have argued that organizations either must accomplish explicit goals and purposes (the goal model) or garner scarce resources (the natural systems model) in order to be effective. ${ }^{5}$ Yet many organizations make money and obtain resources while failing at other important tasks such as adapting to environmental changes and integrating members into the system. Such failures may threaten the organization's future viability even when it is successful in the short-run along the traditional criteria. There is more to being an organization than garnering resources and working toward the present goals of the system. But no overarching framework has been developed which delineates what formal social systems must do in order to remain organized and viable.

An understanding of organizational viability may be acquired by exploring the basic attributes of these systems. Implicit in the goal model is the idea that organizations are purposive while predominant in the natural systems model is the concept of organizational openness. Purposiveness and openness are properties that characterize to some degree all systems from the amoeba to the multinational corporation. ${ }^{6}$ However, these are only two of the many properties of open systems. For example, all systems are characterized by the property of entropy-the tendency to move toward a state of maximum disorder or disorganization. Georgopoulos and Cooke $^{7}$ have argued that general properties of systems such as entropy give rise to problems that systems must solve if they are to survive. The property of entropy, for example, gives rise to the problem of obtaining input. New information and matter-energy must be imported by the system to compensate for that which is lost over time through irreversible processes. ${ }^{8}$ Similarly, the property of openness gives rise to the problem of 
adapting to changes in the environment as well as to the problem of maintaining an internal equilibrium in response to these changes. Failure to solve such problems as input, adaptation, or maintenance perpetuates stress and increases strain within the organization.

Viewed in the context of systems theory, all organizations can be conceptualized as systems which must solve problems that are produced by their attributes or basic properties. Since problems are conditions that involve systemic stress or tension, solving them is necessary for organizational viability. Using the general properties of systems, five sets of problems that arise in and must be solved by organizations can be specified (see Table 1). ${ }^{9}$

\section{Problems of Input, Conversion, and Output}

All systems are faced with the problem of input or the importation of energy from the external environment. ${ }^{10}$ Resources or energy in the form of people, materials, and information must be garnered on a continuing basis by all organizations. These resources are needed to carry out work and to counteract entropy (i.e., to maintain or reorganize the system).

Coupled with the problem of input is that of output. Some product or set of products must be exported across the system's boundaries to other parts of the suprasystem as well as to subsystems (groups and individuals) partially included in the system. This exportation of matter-energy and information enables the system to carry out exchanges which can provide it with new inputs. The need for this exchange arises due to suprasystem and subsystem entropy. Higher- and lower-level systems cannot simply provide the organization with energy; they must also receive energy from it in order to counteract their own entropic tendencies. Societies require the goods and services of organizations to cope with their own problems and members of organizations need remuneration and other rewards in order to maintain their livelihood. Organizations, therefore, face the problem of exporting their products and resources to other systems whose needs render the exports useful.

Given this exchange between the organization and its suprasystem and subsystems, some of the resources imported by the system must be converted for exportation. To have something to export, the organization must process its input in such a way as to add value to it. The addition of value is accomplished through the organization's conversion or throughput process (a critical aspect of an organization's technology). " Thus, organizations must solve conversion problems, including problems associated with selecting and implementing appropriate techniques. The exact nature of these conversion problems depends on the organization's purpose and 
Table 1

A Mapping of Problems and Properties

\begin{tabular}{|c|c|}
\hline Sets of Problems & Related System Properties \\
\hline \multicolumn{2}{|l|}{ I. Input-output } \\
\hline Input & Organizational entropy \\
\hline Conversion & Purpose \\
\hline Output & Subsystem and suprasystem entropy \\
\hline \multicolumn{2}{|l|}{ 11. Control } \\
\hline Input control & $\begin{array}{l}\text { Range of stability, openness, and } \\
\text { environmental interdependence }\end{array}$ \\
\hline Output control & $\begin{array}{l}\text { Range of stability, openness, and } \\
\text { environmental interdependence }\end{array}$ \\
\hline \multicolumn{2}{|l|}{ III. Across subsystems } \\
\hline Coordination & $\begin{array}{l}\text { Subsystem interdependence and } \\
\text { differentiation }\end{array}$ \\
\hline Resource allocation & Subsystem entropy and differentiation \\
\hline \multicolumn{2}{|l|}{ IV. Across system levels } \\
\hline Adaptation & $\begin{array}{l}\text { Openness, interdependence, and } \\
\text { continuity }\end{array}$ \\
\hline Integration & $\begin{array}{l}\text { Partial inclusion and internal and } \\
\text { intersystem differentiation }\end{array}$ \\
\hline \multicolumn{2}{|c|}{ V. Organizational preservation } \\
\hline Maintenance & Entropy and openness \\
\hline Reorganization & Entropy \\
\hline Strain amelioration & Failure to solve other problems \\
\hline
\end{tabular}

the types of tasks being performed as well as on the technical knowledge available concerning task performance.

Problems of Input and Output Control

The problems of input, conversion, and output are associated with the 
basic phases that constitute the organization's work cycle. ${ }^{12}$ Two other problems, however, complicate this work cycle-those of input control and output control. Mechanisms used to solve input control problems buffer the conversion process from uncertainty and variability in inputs. Solutions to out put control problems reduce variability in the quality and quantity of the organization's products or services. ${ }^{13}$

Problems of input and output control arise due to the basic systems property of range of stability. When system variables are forced to the point at which a correction must occur (i.e., beyond their range of stability), a strain is produced in the system. ${ }^{14}$ Input control can reduce the frequency and the magnitude of these strains. Potential inputs with an excess or deficiency of critical characteristics can be filtered out or denied entry into the system. (Admission standards and student selection procedures are used by private universities for this purpose.) Alternatively, inputs can be controlled internally when openness to the environment is great and all potential inputs must be accepted. (The systematic placement of students into advanced or remedial classes is used by public schools for this purpose.) Outputs are similarly controlled in a number of ways; for example, outputs can be subjected to quality control procedures to reduce fluctuations in the quality of products exported to the environment.

The work cycle of organizations, therefore, involves solving problems of input, input control, conversion, output control, and output. These problems are solved through the application of knowledge about (among other things) the nature of inputs, the effects of different procedures or processes on inputs, and the methods appropriate for quality control-all of which represent types of knowledge manifested in the organization's technology. ${ }^{15}$ The application of relevant knowledge can enhance the efficiency with which the organization achieves its purposes; this, however, does not ensure system viability. A variety of other problems also must be resolved on a continuing basis.

\section{Problems with Subsystems: Coordination and Resource Allocation}

Two important problems that must be resolved in organizations directly concern their diverse subsystems and components-coordination and resource allocation. ${ }^{16}$ First, organizations must coordinate in time and space the efforts and activities of critical subsystems and members so that they facilitate the accomplishment of organizational tasks. ${ }^{17}$ The problem of coordination arises as a result of the system properties of differentiation and interdependence. Over time, systems tend to become increasingly complex and elaborate with progressively differentiated components. ${ }^{18}$ These components and the activities they perform are mutually dependent 
and present contingencies for one another. These interdependencies generate a variety of coordination problems including, for example, the problem of articulating the work of third grade teachers with that of fourth grade teachers.

Second, organizations have to allocate resources-including information, materials, and energy - to their various subsystems and members. This problem arises as a result of subsystem entropy and differentiation. ${ }^{19}$ Resources must be allocated to the organization's critical subsystemsthat is, those subsystems that solve problems and carry out specialized processes necessary for the survival of the system. Like the system as a whole, subsystems tend toward disorder and require energy from the outside to maintain and reorganize themselves. Thus, after organizations solve the problem of obtaining energy from their environment and from their members, this energy must be distributed to critical subsystems. This distribution is complicated by the extent to which subsystems are differentiated and address different system problems or stresses. The types of stresses facing a system change over time; consequently, the allocation of resources to those subsystems responsive to current forms of system stress is a continual problem.

\section{Problems across System Levels: Integration and Adaptation}

Lower-level systems, including groups and individuals, are embedded within organizations which, in turn, are embedded within higher-level systems such as the societal suprasystem. This embeddedness creates the potential for at least two cross-level problems that organizational systems must manage. First, they must adapt to instability, change, and uncertainty in their environments. The openness of organizations to their environments and their interdependence with other systems give rise to this problem of adaptation. ${ }^{20}$ Adaptation is complicated because organizations as systems tend toward continuity or internal stability ${ }^{21}$ even though they operate within multiple subenvironments imposing changing and sometimes conflicting demands.

Second, organizations must integrate or bind members into the system and bring about some consistency bet ween the goals of members and those of the organization in order to ensure member involvement and cooperation with organizational requirements. ${ }^{22}$ The problem of integration arises because members are only partially included in the organization ${ }^{23}$ and are likely to have objectives that a re consistent with those of systems other than the focal organization. Solution of the integration problem is complicated by internal differentiation-the tendency for components and subsystems to move toward distinct and often inconsistent goals, ${ }^{24}$ and by intersystem 
differentiation-the tendency of systems at different levels to move toward different processes and goals. ${ }^{25}$

Proper management of the problems of adaptation and integration can greatly enhance system viability. Adaptation may involve, for example, adoption of a new and more efficient technology for conversion processes. A new technology (such as individualized instruction) not only can increase the adequacy of conversion processes but also can promote or facilitate problem solving in related areas (such as input and output control). Integration can similarly enhance problem solving and viability, especially when members are bound into the system by personal objectives that are consistent with those of the organization. Members who accept the organization's objectives are likely to make relatively great contributions to the system. ${ }^{26}$

\section{Problems of Preserving and Perpetuating the Organization: Maintenance, Strain Amelioration, and Reorganization}

Organizational members rely on the techology and structure of the system in order to carry out their work and solve problems. ${ }^{27}$ Task performance and problem solving become difficult, however, if the technologies and structures become disordered (entropy) or if the organization is disturbed by external forces (due to openness). Organizations, therefore, must direct some energy toward (i.e., use some resources for) maintaining themselves. ${ }^{28}$ The application of resources for this purpose is most feasible when "slack resources" are available"29 - that is, when the problems outlined above are resolved without expending all of the system's inputs. Organizations lacking such resources will be less able to maintain their technologies and structures, will find it difficult to subsequently resolve other problems, and may face an unplanned dissolution.

Slack resources also must be used to manage strain in organizations. Strain amelioration is a second-order problem-one that arises due to a failure to resolve any of the more basic problems described above. ${ }^{30}$ For example, strain can arise as a result of a lack of input, poorly coordinated activities, or inappropriate allocation of resources to subsystems. Organizational strain is reduced as the problem creating the strain is addressed and organizational variables are brought back within their range of stability. ${ }^{31}$ However, temporarily unresolved problems can create strain in the organization's subsystems and components, and these strains also must be ameliorated. For example, a shortage of personnel (i.e., failure to solve input and/or resource allocation problems) can lead to role overload and interpersonal conflict. Such stressors can produce strains such as job dissatisfaction and physical illness. If the system is to continue to function 
properly, resources must be directed toward reducing these strains.

Finally, the viability of an organization depends upon its capacity to reorganize itself. The problem of reorganization, like that of maintenance, arises because of the system property of entropy. However, unlike maintenance, which involves only the preservation of existing structures, reorganization involves the establishment of new ones. Solving the problem of reorganization can mean "developing, elaborating, initiating, and revising" the organization's performance programs. ${ }^{32}$ It can also mean altering the more basic structures of the system, including the way in which members are ordered and coupled in terms of roles, norms, communication, and authority. ${ }^{33}$

The problem of reorganization can be solved most adequately in organizations having slack resources. The use of resources for this purpose provides for system growth and development. Systems that are reorganized in consideration of current and expected internal and external changes will be in an advantageous position for solving current and future problems. For example, mechanisms for solving problems that are consistent with an organization's interdependence with its environment, as well as with the characteristics of that environment, facilitate solving the adaptation problem. ${ }^{34}$ Similarly, establishing new structures that are responsive to an organization's internal interdependencies facilitates solving the coordination problem. ${ }^{35}$ More generally, mechanisms that are appropriate with respect to the basic properties of the system will promote organizational problem solving and viability.

\section{PROBLEMS AND PROBLEM SOLVING}

To address the systemic problems described above, organizations use both technology and structure as bases from which to derive solutions. Technology is the application of knowledge to perform work. ${ }^{36}$ In organizations this application of knowledge is reflected in three qualitatively distinct modes or orders of technology: (1) the information and skills possessed by organization members and the equipment they use, (2) the performance programs or procedures that guide and direct activities, and (3) the activities constituting the organization's workflow. ${ }^{37}$ Structure is the ordering and coupling of organizational components, and it is reflected in the patterning and linkages among people, performance programs, or activities.38 For example, people possessing information and skills are ordered and coupled through authority, communication, normative, and role structures. Similarly, performance programs and activities are organized through structures which interconnect and order them in time and space. 
Knowledge, skills, and resources are preconditions for problem solving. ${ }^{39}$ In organizations, these preconditions are largely embedded in the three orders of technology described above. Those resources not embedded in the organization's technology include certain inputs to the organization (e.g., funding or materials) whose acquisition and/or allocation may constitute a large part of any problem's solution. Structures represent means for organizing components and reflect in part the way in which organizational resources (e.g., personnel, information, or power) are distributed. The manner in which components are organized contributes to problem solving in various ways and shapes how effectively the potential of each component is used. Those structures ordering and coupling individuals (e.g., norms and communication) may, for example, enhance or limit the degree to which any individual's knowledge is transmitted, shared, and utilized in the problem-solving process. In facilitating problem solving, certain structures may be more appropriate than others.

Appropriate structures are those that organize a system's technological components (skills, procedures, and activities) in ways that promote task performance and problem solving. The first order of the organization's technology, the knowledge and skills possessed by individuals or collectively by organizational subunits, can represent both a source of innovative ideas as well as a repository of procedures that have been effective in the past. These and other previously established procedures or performance programs (which constitute the second order of organizational technology) may facilitate problem solving by limiting the search processes needed to identify appropriate problem solutions. ${ }^{40}$ Finally, the third order of technology, the activities carried out by the organization (e.g., computerassisted instruction or quality control checks) may provide the means for effecting or altering those conditions that are viewed as organizational stressors (e.g., unmotivated students or poor product reliability).

Technology and structure are used jointly for problem solving. For example, in response to the difficulties involved in teaching reading (part of the generic problem of conversion in schools), staff who possess knowledge regarding the types of reading programs available (technology) and who are linked together by horizontal communication channels and norms supporting staff cooperation (structure) may generate and implement a solution such as a special, intensive training program for problem readers. This type of solution illustrates the way in which structure can provide a base for the application of knowledge (technology). More generally, the application of knowledge and effective problem solving depends on the availability of structures that are appropriate to the problems faced by the organization. 


\section{HYPOTHESES}

This model of organizational problem solving suggested a number of general hypotheses that can be tested in schools. These hypotheses concerned the relationships among organizational inputs, structures, problem solving, and outputs. The inputs considered here were financial (expenditures per pupil) and the outputs included the satisfaction derived by the teaching staff and the performance of students on standardized tests. Structures were considered in terms of the presence of linkages between members that are likely to be appropriate for problem solving-including participative decision making arrangements, strong vertical communication channels, and norms supporting high standards of performance. Problem solving was considered in terms of the perceived adequacy of problem solving in the areas described above.

First, it was hypothesized that funding is positively related to the adequacy of problem solving. High levels of funding make available to schools qualified staff, materials, and other resources which, according to MacCrimmon and Taylor, are critical for the adequate solving of problems. ${ }^{41}$ High funding also can provide residual resources for solving the basic problems of reorganizing the system and maintaining appropriate organizational structures. Thus, it was also hypothesized that funding is positively related to the presence of structures that are appropriate for problem solving. (Behind this hypothesis is the assumption that certain structures, including participative arrangements, are expensive to establish and use on a regular basis..$^{42}$ ) Third, it was hypothesized that the presence of appropriate structures is related to the adequacy of problem solving. Previous theoretical and empirical work has suggested that participative structures, vertical communication, and norms supporting high standards promote effective problem solving. ${ }^{43}$ More recently, these structures have been shown to improve problem-solving processes in experiments designed

1 to assess the impact of structural changes in schools. ${ }^{44}$ Given certain environmental and other differences across schools, there should be some variation in the extent to which these structures are appropriate for solving their particular problems. Additionally, there should be some variation across problem areas with respect to the appropriateness of these structures given the different system properties generating the problems. ${ }^{45}$ Nevertheless, these structures were expected to be positively and significantly related to the adequacy of problem solving in the different areas.

Finally, if problems are adequately solved, organizations are more likely to produce outputs that are valued by the suprasystem (e.g., good performance by students on standardized tests) and by organizational members (e.g., satisfying jobs for teachers). Therefore, it was hypothesized that problem-solving adequacy is positively' related to the production of 
valued outputs. This hypothesis has been supported by research carried out in hospitals ${ }^{46}$ and other service organizations.

\section{METHOD}

In order to test the above hypotheses, the following procedures were employed.

\section{Sample}

A set of 25.public schools was selected to obtain a sample of teachers representative of all those employed in the southeastern quadrant of the lower peninsula of Michigan. All schools in this geographical area were listed in a sampling frame organized first by type of school (elementary, middle/junior high, and senior high school) and then by county. Within each county, schools were listed by size according to number of teachers, alternating from small-to-large to large-to-small between counties. Twenty-five schools were then randomly selected with the probability of selection weighted by the size of each school. The final sample included 11 elementary schools, 6 middle and junior high schools, and 8 senior high schools from 23 different districts.

\section{Instrumentation and Data Collection}

Data were obtained from two major sources. First, information about student achievement and expenditures per pupil was obtained from the Michigan State Department of Education. Student achievement data were provided by the state at both the district and school building levels. Data on expenditures per pupil were provided at the district level only. (In two cases, two schools in the sample were situated within the same district. Therefore, there is a minor dependence-of-observation problem in this (respect.) Second, information about organizational structures and problem-solving adequacy was obtained from eight randomly selected teachers in each of the 25 schools. (These data were collected during the summer months of 1979.) Of the 200 teachers initially selected, 23 (11.5 percent) could not be contacted due to extended vacations or job changes. Another 18 teachers ( 9 percent) preferred not to participate in the study. Additional teachers were randomly selected until eight individuals could be surveyed from each school. The 200 teachers were interviewed, usually in their homes, and then asked to complete and return a self-administered questionnaire. 


\section{Problem-solving Measures}

Problem-solving adequacy in the various areas of the above model was measured through questionnaire items with five-point response scales included in the self-administered questionnaire. At least two, and usually three, questions were asked about each problem area (see Table 2 for a listing of representative items by area). Most of these items were adapted from Coughlan's School Survey47; some were modified from surveys designed to measure problem-solving adequacy in hospital subunits ${ }^{48}$; and others were developed specifically for this study.

These questionnaire items were intended to translate the somewhat general and theoretical problem areas into the more specific and practical problems faced by school personnel. For example, input control was operationalized in terms of the adequacy of student placement, conversion in terms of the appropriateness of instructional methods for the types of students enrolled, and output control in terms of the adequacy of student evaluation and grading procedures. Similarly, coordination items concerned the fit between teaching activities across grade levels and subject areas, and resource allocation questions focused on the adequacy of instructional materials and supplies. The adequacy of problem solving in the area of reorganization was reflected in the extent to which schools established and used the structures previously identified as appropriate for educational systems. The specific questionnaire items used to measure the use of these structures are discussed below.

The questionnaire items were worded to refer to the school rather than to the respondent and were designed to measure organizational rather than individual phenomena. Nevertheless, analyses of variance (by school) were run on the indices based on these items to determine whether variance in responses across schools was greater than that within schools. This procedure has been used in various studies to assess the appropriateness of aggregating individual responses to the organizational level. ${ }^{49}$ These analyses generally showed that the variance across schools was greater than that within schools, suggesting that the variables measured were organizational-level phenomena. Two indices that performed poorly on this test (integration and maintenance) were excluded from subsequent analyses. The remaining indices are listed in Table 3 along with the results of the analyses of variance and their Cronbach-alpha reliabilities. Two indices were included for adaptation-adaptation to the technical sector of the environment (indicating technological innovativeness) and adaptation to the social or community sector. An organization may be differentially open to these two sectors of the environment and the adequacy of its adaptation to these sectors may vary. ${ }^{50}$ 
Table 2

Representative Scale Items

Input Control (Student Placement)

- The students I work with are placed at the instructional level that is best for them.

Conversion (Instructional Appropriateness)

- To what extent are the learning experiences in your school diverse enough to accommodate the needs of all the students?

Output Control (Testing/Grading)

- How adequate are the procedures for evaluating student progress (e.g., achievement tests) in your district?

Coordination

- How well do the instructional activities of those teaching different grade levels fit together in your school?

Resource Allocation (Supplies and Materials)

- I have sufficient supplies for my work.

Adaptation (Technical Sector)

- How well does your school keep up with the changes and innovations that are occurring in education?

Adaptation (Social Sector)

- To what extent has your school been responsive to changes in the needs of the community?

Strain Amelioration (Interpersonal Conflict)

- When disagreements arise about problems facing your school, how well are these disagreements generally worked out?

Vertical Communication

- How much communication is there between the teachers in your school and central office administrators?

Normative Structure

- Everyone in my school is expected to work hard to provide students with the best education possible.

Participation (Managerial Domain)

Please indicate to what extent you participate in...

- Hiring new professional personnel.

- Planning school building budgets.

Participation (Technical Domain)

Please indicate to what extent you participate in ...

- Resolving learning problems of individual students.

- Determining appropriate instructional methods and techniques.

Satisfaction

- If a good friend of yours told you he/she was interested in working in a job like yours, what would you tell him/ her? Would you strongly recommend this job, would you have doubts about recommending it, or would you strongly advise $\mathrm{him} /$ her against this sort of job? 
Table 3

Scale Reliabilities and Analysis of Variance

Scale

\begin{tabular}{cc} 
Alpha $^{a}$ & $\begin{array}{l}\text { ANOVA } \\
\text { F-ratios }\end{array}$ \\
\hline
\end{tabular}

Problem solving:

Input control (student placement)

.63

Conversion (instructional appropriateness)

.74

$3.11^{* * *}$

Output control (grading/testing)

Coordination

Resource allocation (supplies/materials)

Adaptation (technical sector)

Adaptation (social sector)

Strain amelioration (interpersonal conflict)

Structure (adequacy of reorganization):

Vertical communication $\quad .56$

Normative structure

Participation (managerial domain)

Output:

Job satisfaction

${ }^{*} p \leqslant .01$

$* * p \leqslant .001$

$* * * p \leqslant .001$

${ }^{2}$ Internal consistency reliabilities calculated at the level of the individual teacher $(\mathrm{n}=200)$.

${ }^{b}$ Tests whether between-school variance is greater than within-school variance.

\section{Structure Measures}

Vertical communication, normative structure, and participation in decision making were measured through items using five-point scales in the teachers' self-administered questionnaire. Representative items are listed in Table 2 and scale ANOVA's and reliabilities in Table 3. Participation was measured by asking teachers the extent to which they participate in each of a number of different decisions. ${ }^{31}$ Two indices were then 
constructed from these questions-one representing participation in technical or instructional decisions and the other representing participation in managerial decisions. ${ }^{52}$ Vertical communication and normative structure were measured with items from Coughlan's School Survey and other questions developed specifically for this study.

\section{Input and Output Measures}

The organizational input considered here was the amount of money the school district had available and expended per student. This input was measured in terms of total general expenditures per pupil. Across the 25 schools in the sample, this measure correlated .95 with total instructional expenditures per pupil. The general expenditure measure provides a better indication of total financial input than the instructional expenditure measure, which includes only that input allocated to technical activities. (Although the latter measure excludes certain types of expenses that may be incurred and accounted for in different ways from one district to the next and may provide greater comparability across organizations, it is not used here in view of its very strong correlation with the general expenditure measure.) The expenditure data were for the 1977-78 school year and were provided by the Michigan Department of Education. ${ }^{53}$

Outputs from the organization to the suprasystem were measured in terms of student achievement test scores. Two types of measures were used. The first measures reflect the percent of students scoring in the top quartile on standardized statewide math and reading tests. Fourth grade scores were used for the elementary schools, seventh grade scores for the middle and junior high schools, and tenth grade scores for the senior high schools. Information on the percentage of students scoring in the top quartile statewide on both math and reading tests in 1979 was obtained at both the district and school levels. These test scores, provided by the Michigan Department of Education, commonly are viewed by community members as a good estimate of the output or performance of their schools. Many teachers and administrators, however, do not view these scores as adequate indicators of the comparative effectiveness of schools. Comparability of these scores is limited by such things as the socioeconomic status of students and district practices regarding "teaching to the test."

Some of the non-compa rability of these quartile scores is reduced by the second set of measures: district gain scores for reading and math for which previous score levels are controlled. (Note that these residual gain scores were computed only at the district level due to the absence of school-level Jata on previous achievement scores.) Based on changes over a three-year ?eriod in the percent of district students scoring in the top quartile itatewide, these measures are a modified version of an evaluation 
technique designed to estimate the relative effectiveness of schools with different types of students. ${ }^{54}$ For elementary schools, the percent of district students scoring in the top quartile at the fourth grade was used to predict the percent scoring in that quartile at the seventh grade. For secondary schools, the percent scoring in the top quartile at the seventh grade was used to predict the percent scoring in that quartile at the tenth grade. In both cases, the output measure used here is the residual (the unexplained increase or decrease in the percent of students scoring in the highest quartile) which may be attributable to teaching quality or the adequacy of organizational problem solving.

Finally, output from the system to its members was measured in terms of the satisfaction teachers derive from their jobs. Satisfaction was measured with three interview items from the Quality of Employment Survey. ${ }^{55}$ The reliability of the index based on these items was .61 (Table 3).

\section{RESULTS}

Correlational analysis was employed to test the hypotheses of this study as well as to explore the interrelations among the measures of problemsolving adequacy. Intercorrelations among measures of input, structure, problem-solving adequacy, and output are presented in Table 4.

\section{Problem-solving Adequacy}

Since organizational problem solving was a central issue in this study, the nature of the interrelations between measures of problem-solving adequacy were a concern. Intercorrelations among measures of problemsolving adequacy indicated that these variables were in general positively related. These results are consistent with those of Georgopoulos and Mann $^{56}$ and Cooke, Rhodes, and Greenfield, ${ }^{57}$ who focused on a subset of the problems considered here. Thus, the adequacy with which an organization solves one generic problem may be related to how adequately it solves other problems as well. It is noted, however, that method bias probably affected the correlations among the problem areas since all such measures derive from the same questionnaire.

\section{Input and Problem-solving Adequacy}

The first hypothesis asserted that funding is positively related to the adequacy of problem solving. This hypothesis was consistently supported with all but one of the eight correlations between expenditures per pupil and problem-solving adequacy attaining statistical significance $(p \leqslant .05)$. All the correlations were in the predicted direction. 


\section{Input and Structure}

It was also hypothesized that funding is positively related to the presence of structures that are appropriate for problem solving. The results partially supported this hypothesis. Although all of the relevant correlations were positive, only two structural measures yielded statistically significant correlations with funding. Funding was significantly related to the presence of norms for high performance and to participation in managerial decisions. These results suggest that financial resources may be necessary for some organizational structures but not for others. It is also possible that the presence of certain structures facilitates the garnering of resources. Though causality cannot be determined, it can be concluded that funding levels were linked to the presence of certain types of structures.

\section{Structures and Problem-solving Adequacy}

The third hypothesis asserted that the presence of appropriate structures is related to how well problems are solved. Results indicated that this hypothesis was generally supported for two types of structure: vertical communication and high performance norms. The presence of both these structures was positively related to how adequately the school solved problems of input control, conversion, coordination, and social and technical adaptation. Structures for teacher participation in technical decisions correlated with the adequacy of problem solving in instructional areas (i.e., input control and conversion) but not with problem solving in most of the other areas. With one exception, teacher participation in managerial decisions was not significantly related to problem-solving adequacy. While these latter findings provide only minimal support for the hypothesized relationship between participative structures and problemsolving adequacy, they are consistent with previous work suggesting that teacher participation is more appropriate in instructional than in managerial decisions..$^{58}$

\section{Problem-solving Adequacy and Outputs}

Finally, problem-solving adequacy was hypothesized to be positively related to the production of valued outputs. Results indicated that measures of problem-solving adequacy tended to correlate positively with the various output indices. Regarding output valued by the suprasystem, school and district reading and math scores generally correlated significantly with problem-solving adequacy in four areas: input control, conversion, out put cont rol, and coordination. Interestingly, reading scores correlated less highly with measures of problem-solving adequacy than did 


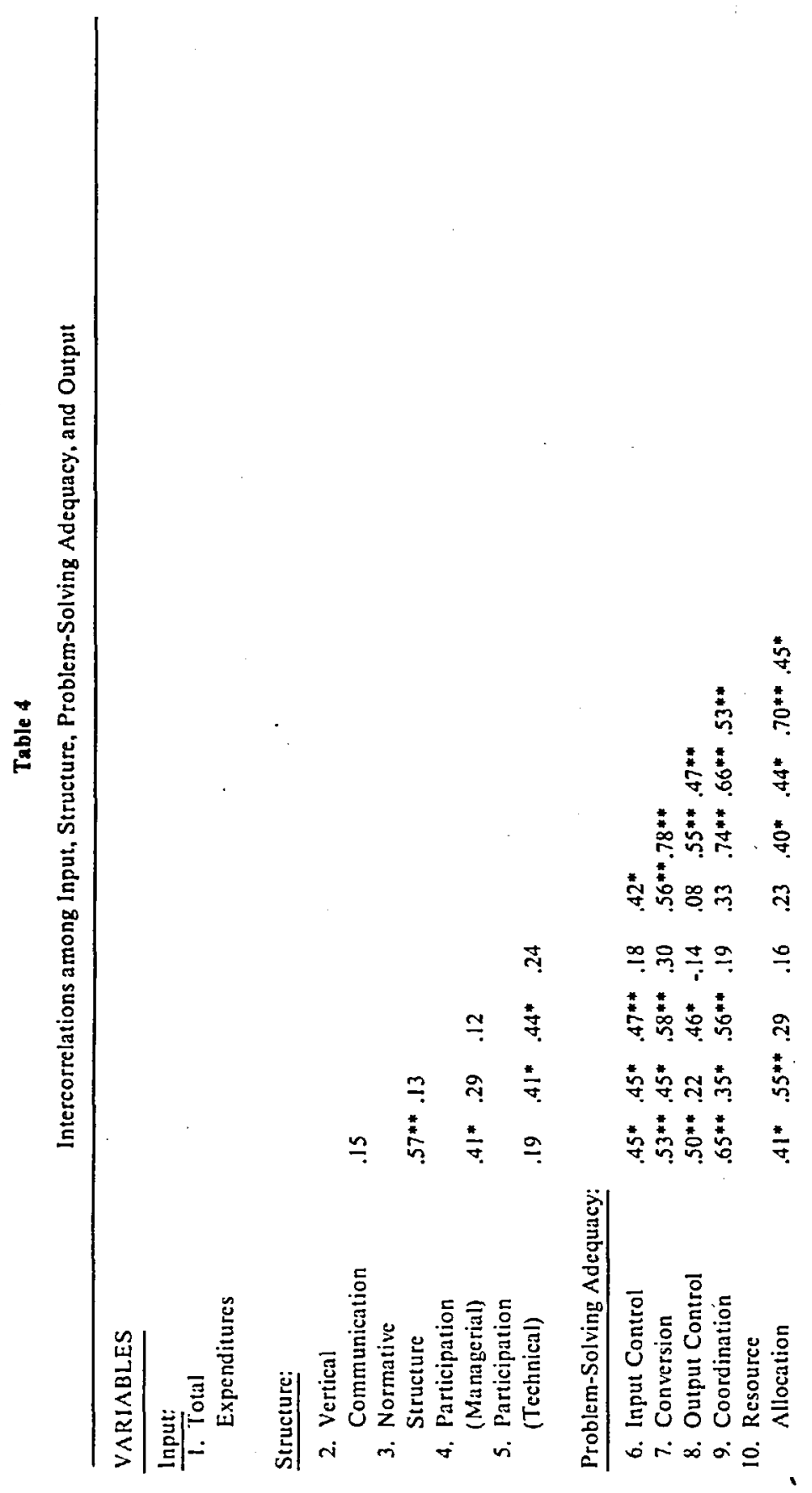




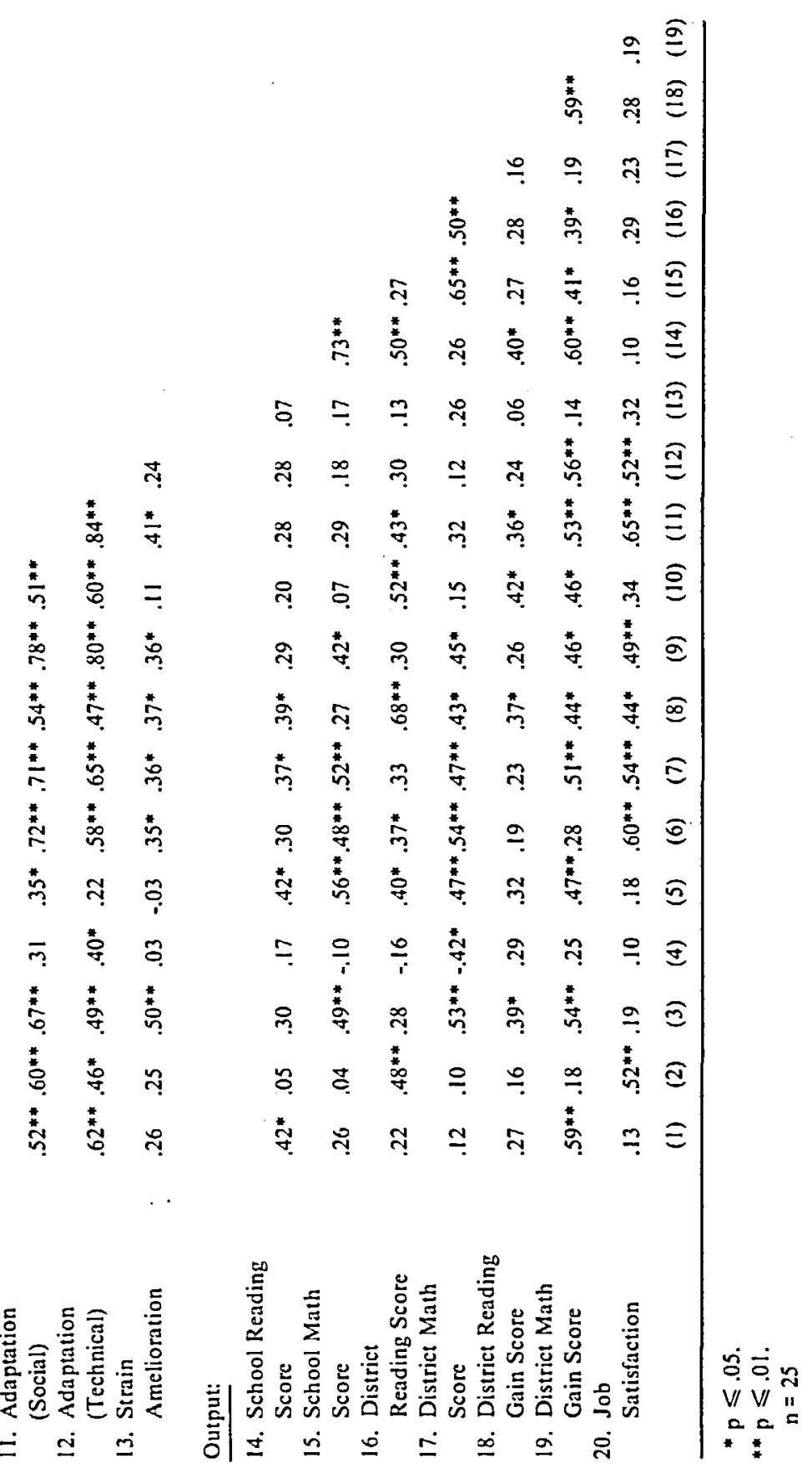


math scores. This stronger relationship between math scores and problemsolving adequacy may be a function of the greater influence exerted by schools on the acquisition of math skills. Verbal skills may be influenced by non-school fact ors such as child-rearing practices (e.g., when parents read to their children or teach them to read) while math skills may be primarily acquired in school. Alternatively, math skills may be more easily measured. It is noteworthy that this pattern of relations was upheld for the gain score measures which, by controlling for previous levels of reading and math achievement, may better reflect those aspects of student performance attributable to school-related factors. ${ }^{39}$

Teacher satisfaction, a measure of system output from the perspective of its members, was significantly related to all but two measures of problemsolving adequacy. (This finding is in part attributable to methods bias since teacher satisfaction and problem-solving adequacy were assessed through the same data source.) Although teacher satisfaction was not significantly related to any measure of reading or math achievement, those measures of problem-solving adequacy associated with high student achievement were also associated with high teacher satisfaction. These findings suggest that the problem solutions that promote student performance on tests may also enhance teacher satisfaction.

In general, the results described above provided support for the hypotheses of this study. However, they also suggest that different structures may not be equally dependent upon the availability of funds: per-pupil expenditures were linked to the presence of norms supporting high standards of performance and to participation in managerial decisions, but not to vertical communication or participation in technical decisions. Additionally, structures were differentially related to how well schools solve problems: vertical communication and high performance norms correlated strongly with problem-solving adequacy, but managerial participation did not. Nonetheless, there was evidence of significant and positive relations between financial inputs and certain school structures, between certain structures and problem-solving adequacy, and between problem-solving adequacy and outputs that are valued by teachers and the community. ${ }^{60}$

\section{DISCUSSION}

The model of system problem solving presented here highlights the importance of resources and structures in problem solving. It suggests that one cannot simply "throw money at a problem." Rather, how the money is used does affect both how well problems are solved and what is accomplished. The present study provides evidence that the ways in which a system is organized may make a difference in terms of the outputs 
produced. Inputs to a system may not themselves determine what the system's output will be or how much of it will result.

These findings indicate that high performance norms and vertical communication structures are related to how well problems are solved. Funding is also related to problem-solving adequacy, partly because funding may permit the establishment and use of structures that facilitate problem management. Further, financial inputs may enable the organization to acquire other resources that are necessary for adequate problem solving in general (e.g., highly-qualified staff) or necessary for the solution of specific problems (e.g., modern instructional equipment).

The results of this study have a number of implications for educational administrators, teachers, and researchers interested in organizational behavior in schools. For researchers, the results indicate that organizational theory-and, more specifically, organizational systems theory-can provide a meaningful framework for und erstanding the structuring and functioning of schools. Some of the early work treating schools and other organizations as systems was not particularly helpful in this respect. In some cases, the linkages between critical variables (e.g., properties and problems) were not specified; in other cases, numerous variables were presented, all of which were expected to be interrelated in some unexplained way. This article develops an explanatory framework based on systems concepts which hypothesizes relationships among a limited number of variables. The empirical test of these hypotheses suggests that the proposed model is viable but requires further elaboration and refinement.

One area for further research concerns the link between system properties and the difficulty of the problem to be solved. Some schools show more adequate problem solving than others, but the problems faced by the former schools may be less difficult than those faced by the latter. A second area for further research concerns the factors that explain why certain schools with high levels of expenditures per pupil exhibit appropriate structures while others do not. These factors might range from the leadership styles administrators use to the constraints imposed by school boards or contracts with teachers' organizations. Other a reas for research include: the way in which classroom variables intervene between problemsolving adequacy and school output; the ways in which variables like school size affect structures and problem solving; the mechanisms used by certain schools with low per-pupil expenditures to adequately solve problems; and the relationship of problem-solving adequacy to other output variables including student satisfaction and self-esteem.

For administrators, the results of this study indicate that structural changes-particularly those directed toward norms and vertical communication-might lead to improvements in the viability and outputs of their schools. Thus, when preparing budgets, administrators (and school 
boards) should consider allocating some funds to school reorganization and structural development. Additionally, administrators should consider the ways in which they are allocating and utilizing their time. Some administrators may be spending too much time dealing directly with technical problems and not enough time on problems of maintaining and rebuilding their organizations. Time spent on reorganization could translate into better technical problem solving by the teaching staff and, indirectly, could provide the administrator with more time to deal with managerial problems (e.g., relations with the community).

For teachers, the results of this study indicate that their job satisfaction is linked to the same variables as is the performance of their students. The correlations between job satisfaction and student performance are positive but not significant; nevertheless, both of these outputs are significantly related to problem-solving adequacy. Thus, teacher dissatisfaction may be indicative of conditions within the school that are related to poor student performance. Dissatisfied teachers therefore might act to promote organizational change programs that are directed toward structural change and better problem solving. ${ }^{61}$ Such programs, although sometimes unsuccessful, may improve not only the quality of their work lives but also the quality of their work performance.

While this article has addressed issues pertaining to the solving of school problems by teachers and administrators, it began by developing a generic model applicable to diverse types of organizations or systems. The researchers moved from a general theory of system problem solving to issues of funding, structural appropriateness, and output assessment specific to schools. In many ways, schools provide an ideal setting for developing, testing, and refining models of organization and administration. Schools operate in diverse environments, serve many constituencies, and differ greatly in the resources available to them and the outputs they produce. Because of both their complexity and intrinsic importance, schools are fertile arenas for organizational research. The results of the present study suggest that research on schools can enhance our understanding of organizational systems in general.

\section{NOTES}

1. The data reported in this paper were collected as part of a study on the Quality of Work Life of Teachers which was funded by the U.S. Department of Labor (Contract Numbers 41-NSC-252C3 and J9-M9-0124; H. Kornbluh and R. Cooke, Principal Investigators). The preparation of this article was made possible by support from the Naval Postgraduate School Research Foundation and Stanford University. (The opinions expressed in this article do not necessarily reflect those of the funding agencies.) The authors extend thanks to Carl Goble, Hy Kornbluh, and Don Spangler for their contributions to this 
research and to Carson Eoyang, J. D. Eveland, Karlene Roberts, and W. R. Scott for their helpful comments on an earlier version of this paper.

2. P. J. Runkel, R. A. Schmuck, J. H. Arends, and R. P. Francisco, Transforming the School's Capacity for Problem Solving (Eugene, Ore.: Center for Educational Policy and Management, 1978); and B. R. Hampton and R. H. Laner, Solving Problems in Secondary School Administration: A Human Organization Approach (Rockleigh, N.J.: Longwood, 1981).

3. Several writers have addressed these issues. See, for example, B. S. Georgopoulos and R. A. Cooke, "A Conceptual-Theoretical Framework for the Organizational Study of Hospital Emergency Services," Ann Arbor, Mich.: Institute for Social Research Working Paper Series, The University of Michigan, 1979; and D. Katz and R. L. Kahn, The Social Psychology of Organizations (New York: Wiley, 1966, 1978).

4. Georgopoulos and Cooke, "A Conceptual-Theoretical Framework"; D. M. Rousseau, "Assessment of Technology in Organizations: Closed versus Open Systems Approaches," Academy of Management Review 4 (October 1979): 531-542; B. S. Georgopoulos, Organizational Research on Health Institutions (Ann Arbor, Mich.: Institute for Social Research, 1972); J. D. Thompson, Organizations in Action (New York: McGraw-Hill, 1967); and Katz and Kahn, The Social Psychology of Organizations.

5. The goal model is described by A. Etzioni, Modern Organizations (Englewood Cliffs, N.J.: Prentice-Hall, 1964); and the natural systems model by E. Yuchtman and S. E. Seashore, "A Systems Resource Approach to Organizational Effectiveness," American Sociological Review 32 (December 1967): $891-903$.

6. J. G. Miller, Living Systems (New York: McGraw-Hill, 1978).

7. Georgopoulos and Cooke, "A Conceptual-Theoretical Framework," pp. 2-4.

8. Katz and Kahn, The Social Psychology of Organizations; and L. von Bertalanffy, General Systems Theory (New York: George Braziller, 1968).

9. Many of the problem areas discussed in this article have been previously delineated by B. S. Georgopoulos, Organizational Research on Health Institutions. These problems include adaptation, coordination, integration, maintenance, resource allocation, and strain amelioration. The problems of input control and output control have previously been proposed by D. M. Rousseau, "Assessment of Technology in Organizations." Input, conversion, output, and reorganization have not previously been treated as problem areas; the first three, however, have been cited as defining characteristics of social systems by Katz and Kahn, The Social Psychology of Organizations.

10. See, for example, K. B. DeGreene, Sociotechnical Systems (Englewood Cliffs, N.J.: Prentice-Hall, 1974); and R. A. Ullrich and G. F. Wieland, Organization Theory and Design (Homewood, IIl.: Irwin, 1980).

11. Rousseau, "Assessment of Technology in Organizations," p. 532.

12. See, for example, DeGreene, Sociotechnical Systems; and Rousseau, "Assessment of Technology in Organizations." 
13. Thompson, Organizations in Action.

14. Miller, Living Systems, p. 34.

15. Rousseau, "Assessment of Technology in Organizations," p. 531.

16. S. Becker and C. Gordon, "An Entrepreneural Theory of Formal Organizations," Administration Science Quarterly 11 (December 1966): 315-344.

17. Several writers have written about the need for coordination. See, for example, R. Cooper and M. Foster, "Sociotechnical Systems," American Psychologist 26 (July 1971): 467-474; F. E. Emery, Characteristics of Sociotechnical Systems (London: Tavistock, 1959); and Georgopoulos, Organizational Research.

18. Miller, Living Systems; and Thompson, Organizations in Action.

19. Miller, Living Systems; T. Parsons, "Some Ingredients of a General Theory of Formal Organization," in A. W. Halpin, ed., Administrative Theory in Education (New York: Macmillan, 1958); and Georgopoulos and Cooke, "A Conceptual-Theoretical Framework."

20. Georgopoulos, Organizational Research on Health Institutions; P. R. Lawrence and J. W. Lorsch, Organization and Environment (Homewood, Ill.: Irwin, 1971); and F. E. Emery and E. L. Trist, "The Causal Texture of Organizational Environments," Human Relations 18 (February 1965): 21-32.

21. Georgopoulos, Organizational Research on Health Institutions.

22. B. S. Georgopoulos, Hospital Organization Research: Review and Source Book (Philadelphia, Pa.: W. B. Saunders, 1975).

23. F. H. Allport, Institutional Behavior (Chapel Hill: University of North Carolina Press, 1933).

24. J. G. March and H. A. Simon, Organizations (New York: Wiley, 1958).

25. Miller, Living Sy'stems, p. 28.

26. C. Argyris, "Personality and Organization Theory Revisited," Administration Science Quarterly 18 (June 1973): 141-167.

27. D. M. Rousseau and R. A. Cooke, "Technology and Structure," Institute for Social Research Working Paper Series, The University of Michigan, 1980.

28. Georgopoulos, Hospital Organization Research, p. 130.

29. R. M. Cyert and J. G. March, A Behavioral Theory of the Firm (Englewood Cliffs, N.J.: Prentice-Hall, 1963).

30. Georgopoulos and Cooke, "A Conceptual-Theoretical Framework,"p. 7.

31. Miller, Living Systems.

32. March and Simon, Organizations, p. 170.

33. Georgopoulos and Cooke, "A Conceptual-Theoretical Framework."

34. See, for example, T. Burns and G. M. Stalker, The Management of Innovation (London: Tavistock, 1961); and G. Zaltman, R. Duncan, and J. Holbek, Innovations and Organizations (New York: Wiley Interscience, 1973). 
35. A. H. Van de Ven and A. Delbecq, "Determinants of Coordination Modes within Organizations," American Sociological Review 41 (April 1976): 322-338.

36. Rousseau, "Assessment of Technology in Organizations."

37. Rousseau and Cooke, "Technology and Structure."

38. Georgopoulos and Cooke, "A Conceptual-Theoretical Framework."

39. K. R. MacCrimmon and R. N. Taylor, "Decision Making and Problem Solving," in M. D. Dunnette, ed., Handbook of Industrial and Organizational Psychology (Chicago: Rand McNally, 1976).

40. March and Simon, Organizations.

41. MacCrimmon and Taylor, "Decision Making and Problem Solving."

42. D. L. Duke, B. K. Showers, and M. Imber, "Teachers and Shared Decision Making: The Costs and Benefits of Involvement," Educational Administration Quarterly 16 (Winter 1980): 93-106.

43. See, for example, R. Likert, The Human Organization: Its Management and Value (New York: McGraw-Hill, 1967); and W. D. Hawley, "Dealing with Organizational Rigidity in Public Schools: A Theoretical Perspective," Unpublished manuscript, Yale University, New Haven, Undated.

44. R. A. Cooke and R. J. Coughlan, "Developing Collective Decision-Making and Problem-Solving Structures in Schools," Group and Organization Studies 4 (March 1979): $71-92$.

45. E. M. Hanson and M. E. Brown, "A Contingency View of Problem Solving in Schools: A Case Study," Educational Administration Quarterly 13 (Spring 1977): 71-91.

46. B. S. Georgopoulos and R. A. Cooke, A Comparative Study of the Organization and Performance of Hospital Emergency Units (Ann Arbor: Institute for Social Research Technical Report Series, The University of Michigan, 1980).

47. R. Coughlan and R. A. Cooke, "Work Attitudes," in H. Walberg, ed., Evaluating Educational Performance (Berkeley, Calif.: McCutchan, 1974).

48. B. S. Georgopoulos and R. A. Cooke, A Comparative Study.

49. See, for example, B. S. Georgopoulos and A. S. Tannenbaum, "A Study of Organizational Effectiveness," American Sociological Review' 22 (October 1957): 536-540; J. A. Drexler, "Organizational Climate: Its Homogeneity within Organizations," Journal of Applied Psychology 62 (1977): 38-42; B. Schneider, "Problems and Pitfalls: Same Data, Different Levels of Analysis," Paper presented at the American Psychological Association Convention, Toronto, 1978; and K. H. Roberts, C. L. Hulin, and D. M. Rousseau, Developing an Interdisciplinary Science of Organizations (San Francisco: Jossey-Bass, 1978).

50. N. E. Uzun, "Significance of Environment to Organizations: Proposing a Model for Studying Environment in Relation to Organizations," Unpublished manuscript, The University of Michigan, Ann Arbor, 1979. 
51. J. A. Alutto and J. A. Belasco, "Patterns of Teacher Participation in School System Decision Making," Educational Administration Quarterly 9 (Winter 1973): $27-41$.

52. A. M. Mohrman, R. A. Cooke, and S. A. Mohrman, "Participation in Decision Making: A Multidimensional Perspective," Educatonal Administration Quarterly 14 (Winter 1978): 13-29.

53. Total general expenditures comprises all accounts for operating a school district including current operating expenditures, community services, and capital outlay. For further details on the meaning of this variable, see Michigan Department of Education, "Ranking of Michigan Public High School Districts by Selected Financial Data, 1976-1977," Bulletin 1012 (Lansing, Mich., author, 1978).

54. H. Walberg, ed., Evaluating Educational Performance (Berkeley, Calif.: McCutchan, 1974).

55. R. P. Quinn and G. L. Staines, The 1977 Quality of Employment Survey (Ann Arbor: Institute for Social Research, The University of Michigan, 1979).

56. B. S. Georgopoulos and F. C. Mann, The Community General Hospital (New York: Macmillan, 1962).

57. R. A. Cooke, G. L. Rhodes, and A. Greenfield, "Organizational Problem Solving and the Implementation of a Patient's Rights Protection System," Paper presented at the Academy of Management Convention, Detroit, 1980.

58. E. M. Bridges, "A Model for Shared Decision Making in the School Principalship," Educational Administration Quarterly 3(Winter 1967): 49-61; and J. P. Savedoff, "The Distribution of Influence and its Relationship to Relevance, Expertise, and Interdependence in Educational Organizations," Ph.D. dissertation, The University of Michigan, 1978.

59. The correlations between the measures of problem-solving adequacy and the gain scores are important for another reason. These correlations make less plausible an alternative explanation of the problem-solving adequacy-student performance relationship: that knowing how well students did on standardized tests leads teachers to report high problem-solving adequacy when scores are high and low problem-solving adequacy when scores are low. Since teachers do not know the gain scores associated with their schools, correlations between test scores and problem-solving adequacy can more readily be attributed to the effect solving problems has on student performance.

60. An area not touched on by this study's hypotheses is the connection between structure and output. Results presented here indicate that, in general, structures are positively related to outputs. However, there is one exception: participation in managerial decisions was negatively related to several output measures, in one case significantly. One explanation for this finding is that when schools are ineffective in meeting the needs of their members (students or teachers), teachers may attempt to increase their influence through political action expanding their involvement in managerial and ad minist rative decision 
making. This type of political action, discussed by Mohrman, is consisten with the negative correlations observed here between participation in mana gerial decisions and certain output measures (See S. A. Mohrman, "A Ner Look at Participation in Decision Making: The Concept of Political Access, Paper presented at the Academy of Management Convention, Atlanta, 1979]

61. See, for example, E. F. Huse, Organization Development and Change, secon edition (St. Paul: West, 1980). 